\title{
Jovem Aprendiz: O adolescente no mercado de trabalho - Reflexões
}

\author{
Young Apprentice: Adolescents in the labor market - Reflections \\ Joven Aprendiz: Adolescentes en el mercado laboral - Reflexiones
}

\section{Resumo}

$\mathrm{O}$ artigo tem como objetivo destacar a relevância do projeto jovem aprendiz como uma maneira de inserir os jovens no mercado de trabalho. A sociedade vem passando por uma grande mudança nas formas de trabalho e na maneira de conseguir um emprego. Ao pontuar adolescência no contexto individual e social, conceituar trabalho e explanar sobre mercado de trabalho, faz-se necessário, no cenário econômico social brasileiro discorrer sobre a lei da aprendizagem, o Projeto Jovem Aprendiz. Essa traz a obrigatoriedade de empresas contratarem jovens, oferecendo incentivo fiscal; associa atividade remunerada à qualificação técnico-profissional metódica, contribuindo no combate a problemas sociais e econômicos, e para a perspectiva de vida de jovens, inclusive na escolha de área de atuação profissional, como é o caso de jovens que atuaram no Ministério Público que seguiram carreira jurídica.

Palavras-chave: Adolescência; Trabalho; Mercado; Aprendiz; Ministério público.

\begin{abstract}
The article aims to highlight the relevance of the young apprentice project as a way to insert young people into the labor Market. Society has been going through a big change in the ways of working and the way to get a job. When punctuating adolescence in the individual and social context, conceptualizing work and explaining about the labor market, it is necessary, in the Brazilian social economic scenario, to discuss the law of apprenticeship, the Young Apprentice Project. This brings the obligation for companies to hire young people, offering tax incentives; associates paid activity with methodical technical-professional qualification, contributing to the fight against social and economic problems, and to the life perspective of young people, including in the choice of professional practice area, as is the case of young people who worked in the Public Ministry who followed legal career.
\end{abstract}

Keywords: Adolescence; Work; Marketplace; Apprentice; Public ministry.

\section{Resumen}

El artículo tiene como objetivo resaltar la relevancia del proyecto de jóvenes aprendices como una forma de insertar a los jóvenes en el mercado laboral. La sociedad ha experimentado un cambio importante en las formas de trabajar y en la forma de conseguir un empleo. Al puntuar la adolescencia en el contexto individual y social, conceptualizar el trabajo y explicar sobre el mercado laboral, es necesario, en el escenario socioeconómico brasileño, hablar de la ley del aprendizaje, el Proyecto Joven Aprendiz. Esto obliga a las empresas a contratar a jóvenes, ofreciendo incentivos fiscales; Asociados actividad remunerada con calificación técnico-profesional metódica, contribuyendo a la lucha contra los problemas sociales y económicos, y a la perspectiva de la vida de los jóvenes, incluso en la elección del área profesional, como es el caso de los jóvenes que laboraron en el Ministerio Público que siguió la carrera jurídica.

Palabras clave: Adolescência; Trabajo; Mercado; Aprendizaje; Ministerio público. 


\section{Introdução}

Diante da contemporaneidade e do novo mercado de trabalho que vem sendo desenhado e desenvolvido de acordo com as mudanças econômicas, políticas e sociais, explanar acerca da adolescência pontuando os adolescentes como colaboradores no mercado de trabalho, tornou-se emergente.

A adolescência é uma fase da vida do indivíduo onde coexistem inúmeras mudanças tanto sociais, como físicas, emocionais e psicológicas que são necessárias para o desenvolvimento do cidadão contribuindo na sociedade.

No contexto social, hoje o adolescente é considerado um indivíduo único que precisa ter suas necessidades individuais resguardadas e perspectivas de futuro.

No contexto político e econômico, países em desenvolvimento incentivam o ingresso de adolescentes e jovens no mercado de trabalho, como o Brasil. Seja para oferecer oportunidades com qualificação profissional, seja como assistência às famílias consideradas em situação precária, seja como reabilitação de jovens infratores, entre outras finalidades, foi estabelecido por lei o projeto Jovem Aprendiz.

Esse projeto apresenta inúmeras peculiaridades que são consideradas positivas tanto para os jovens como para as empresas que contratam. A educação está diretamente associada a este projeto, que possui como principal objetivo direcionar jovens na faixa etária entre 14 e 24 anos para o mercado de trabalho, oferecendo a esses, perspectivas de um futuro e colaborando para que o jovem experimente algumas áreas de atuação profissional, como é o caso de alguns jovens que ao atuarem no Ministério Público, se identificaram com a carreira jurídica e buscaram formação na área.

Dentro dessa perspectiva, adolescência, jovens, mercado de trabalho, Jovem Aprendiz, Ministério Público, o estudo se justifica pela necessidade de multiplicação do conhecimento acerca da adolescência, dos novos rumos do mercado de trabalho, da lei da aprendizagem e seus desdobramentos. Para tal, a revisão de literatura visa conceituar adolescência e essa no contex to social; discorrer sobre trabalho e mercado de trabalho; multiplicar o conhecimento sobre a lei da aprendizagem e o Jovem Aprendiz; pontuar sobre esse projeto no Ministério Público.

\section{Metodologia}

A metodologia utilizada neste estudo foi revisão de literatura, considerando como campo de pesquisa o fenômeno da adolescência, conceitos e história, trabalho, mercado de trabalho, Estatuto da Criança e do Adolescente, A Lei do Jovem Aprendiz (Lei no 10.097) e seus desdobramentos.

A pesquisa bibliográfica, ou de fontes secundárias, abrange toda bibliografia já tornada pública em relação ao tema de estudo, desde publicações avulsas, boletins, jornais, revistas, livros, pesquisas, monografias, teses, material cartográfico etc. [...] Dessa forma, a pesquisa bibliográfica não é mera repetição do que já foi dito ou escrito sobre certo assunto, mas propicia o exame de um tema sob novo enfoque ou abordagem, chegando a conclusões inovadoras (Lakatos, Marconi, 2010, p.166).

Foram selecionadas publicações, estudos, pesquisas, periódicos e trabalhos acadêmicos, artigos, resenhas de livros acerca do tema e de seus aspectos relevantes, utilizando a palavras-chave como adolescência, trabalho, mercado de trabalho, Jovem Aprendiz em bases de dados como Pubmed, SciELO e Google Scholar, entre outras.

Observou-se haver grande quantidade de literatura sobre o tema abordado, porém pouca que relacione os termos pesquisados.

No primeiro momento foi realizada a pré-seleção caracterizada pela rápida leitura que excluiu os que não se encaixavam nos critérios de seleção utilizados que foram textos contento apenas declarações e opiniões não embasadas sobre o tema, textos voltados para outras áreas de conhecimento como psiquiatria, psicologia e educação. 
Após a pré-seleção, foi feita a revisão literária incluindo pesquisa exploratória dos textos, pontuando as questões relevantes que compunha os objetivos propostos. Comparou-se essa análise textual com os resultados de estudos estatísticos sobre o projeto Jovem Aprendiz. Dessa forma conceituou-se adolescência e suas características, trabalho discorrendo acerca do mercado de trabalho, caracterizou-se a Lei do Jovem Aprendiz, pontuando aspectos positivos e negativos utilizando dados estatísticos e desdobramentos como o jovem aprendiz no Ministério Público e essa relação como fundamento para futura carreira jurídica desses jovens.

\section{Resultados e Discussão}

\section{Adolescência}

A adolescência é um período conturbado que envolve questões biológicas, psicológicas e sociais. Segundo a Organização Mundial da Saúde (OMS) (1965), essa fase o desenvolvimento humano compreende a segunda década da vida, dos 10 aos 20 anos e assim concorda o Ministério da Saúde Brasileiro. (OMS, 1965). Porém para o Estatuto da Criança e do Adolescente (ECA), a adolescência compreende dos 12 aos 18 anos. (Brasil, 2007)

De acordo com Santos (2005), o conceito e adolescência refere-se a Biologia, seguindo a idade a as mudanças que acontece no corpo. Na visão de autores como Berger e Thompson (1997), somente a idade não garante o amadurecimento e transformação do indivíduo em adulto. Assim como Martins, Trindade e Almeida (2003); Santos (2005) concordam que aquela compreende transformações cognitivas, de perspectivas e sociais, muitas transformações que atingem também os familiares e a comunidade onde o adolescente está inserido.

Observa-se que essa fase depende dos aspectos cultural e histórico, ou seja, do gênero, da classe social, da geração a qual pertence para ser vivida de diversas formas. E nesse período a escola, mesmo sendo obrigatória, é vivenciada de forma diferente por cada ser e proporciona recursos pessoais como descoberta de oportunidades, hábitos de saúde e interações sociais influenciando individualmente no modo de ver a vida e perspectivas de futuro. (Martins, 2003; Marturano, Elias \& Campos, 2004; Serra, 1997).

Segundo teóricos como Moraes e Moura, existem mesmo na contemporaneidade grupos sociais que acreditam que os adolescentes e jovens são seres de enorme importância, não podem ser entendidos pela sociedade como pessoas. (Morais; Moura, 2007)

A relação entre adolescência e sociedade perpassa os séculos e é objeto de estudo de muitos teóricos como por exemplo Rappaport (1982) que considera uma invenção cultural, Gallantin (1978) diz que a adolescência e sua concepção estão vinculadas a democratização da educação e ao surgimento das leis trabalhistas.

Pesquisas revelam que as culturas mais tecnicamente sofisticadas atrasam o ingresso dos jovens na cultura exigindo sempre mais capacitação e estudos para que esses ingressem no mercado de trabalho, porém nas culturas menos desenvolvidas acontece o oposto, a adolescência está sendo encurtada, pois já existem políticas de ingresso de jovens no mercado de trabalho, como é o caso, no Brasil, do Jovem Aprendiz.

\section{Trabalho - conceito e mercado de trabalho}

Conceitua-se trabalho como sendo toda e qualquer ação ou atitude que o homem realiza na natureza para transformála de acordo com seus interesses e necessidades.

Segundo Carl Marx, o trabalho é uma condição de existência de produção social e possui três aspectos que são característicos: a atividade que é estabelecida e moldada para se atingir um determinado fim; o objeto de trabalho; e o instrumento de trabalho, os meios utilizados para se atingir o trabalho. (Marx, 2002). 
Nesse aspecto, todo trabalho traz prejuízo de energia tanto psíquica quanto física, a essa dá-se o nome de força de trabalho. Portanto, o processo de trabalho engloba a força de trabalho, meios de produção e objeto que vão caracterizar a produção de determinada economia.

De acordo com Nogueira (2006), o trabalho capacita o ser humano a ser consciente, se apresentando de inúmeras formas para atender as necessidades de cada momento histórico.

Acrescenta-se Luckás (1981),

"O trabalho, como formador de valores de uso, como trabalho útil, é uma condição de existência do homem, independente de quaisquer formas de sociedade, é uma necessidade natural eterna que tem a função de mediar o intercâmbio entre o homem e a natureza, isto é, a vida dos homens" (Lukács, 1981, p. 04, apud Nogueira, 2006, p. 139).

Diante a afirmativa, ressalta-se o modo de produção capitalista, no qual o trabalho passou a ser exercido com o objetivo de produzir riquezas.

Na contemporaneidade, houve uma reestruturação do mercado de trabalho para uma visão neoliberal e de produção flexível, na qual o emprego informal, temporário e terceirizado alavanca enquanto que o formal entra em queda. Somado a essa, nota-se que as inovações tecnológicas adentram o mercado de trabalho, tanto no processo quanto na produção.

De acordo com Alves (2007) a lógica desenvolvida nessas condições pela produção capitalista exige novas habilidades comportamentais e cognitivas dos trabalhadores.

Geralmente, a "questão social" que o mercado de trabalho envolve, passa das mãos do Estado, que se desresponsabiliza para as mãos do Terceiro Setor que compreende as Organizações Não Governamentais até entidades beneficentes.

Teóricos concordam que a inserção no mercado de trabalho de jovens e adolescentes em países menos desenvolvidos ocorre mais cedo pela situação econômica das famílias enquanto que em países mais desenvolvidos a exigência de qualificações aumenta o tempo de estudo daqueles.

Nessa, dentre outras finalidades, o Brasil criou o programa Jovem Aprendiz pela Lei 10.097/2000.

\section{A lei da aprendizagem, $O$ Jovem Aprendiz}

Conceitua-se contrato de aprendizagem como uma modalidade especial de contrato de trabalho, por escrito e com tempo determinado, sendo esse não superior a 2 anos em que o empregador assegura oferecer formação técnico-profissional metódica para o desenvolvimento do aprendiz na função, considerado aqui como aprendiz o jovem de idade maior de 14 e menor de 24 anos. (Rosado, 2016)

Segundo Rosado (2016), esse tipo de contratação foi prevista pela Consolidação da Lei do Trabalho e pelo Estatuto da Criança e do Adolescente, e foi regulamentada pelo Decreto Lei 5.598/05. (A Lei do Jovem Aprendiz -Lei no 10.097 - é uma lei que foi aprovada em 2000 e passou por uma regulamentação no ano de 2005). (Rosado, 2016).

Esse contrato visa oferecer maiores oportunidades de inserção no mercado de trabalho dos jovens de faixa etária entre 14 e 24 anos de idade, e qualificação de mão-de-obra nacional, pois durante o contrato os contemplados fazem cursos de especialização oferecidos pelo programa colaborando para a descoberta de habilidades profissionais, potencialidades e para o desenvolvimento do indivíduo quanto cidadão.

Porém esse tipo de contratação tem suas peculiaridades, dentre elas: as empresas devem empregar a quantidade de jovens que esteja entre 5 a $15 \%$ do total de empregados, sendo que é necessário oferecer também cursos nos Serviços Nacionais de Aprendizagem (entidades de formação técnico-profissional metódica como SENAT, SENAC e SENAI); as 
empresas devem destinar aos jovens cargos que necessitem de formação profissional, sendo exclusos cargos de gestão, gerência e confiança; o aprendiz deve ser maior de 14 anos e menor de 24 anos e deve estar matriculado e frequentando a escola; objetiva a formação técnica e profissional dos jovens; o princípio constitucional de igualdade deve ser observado e é vedado qualquer tipo de discriminação. (Camargo, 2016)

Com relação as características, outras peculiaridades são: é um contrato especial, por escrito com validade de, no máximo, 2 anos. A contratação deve ser feita pelo estabelecimento, diretamente; a modalidade não pode ser alterada por prazo indeterminado; o contrato deve constar na Carteira de Trabalho e Previdência Social (CTPS), matrícula e frequência escolar.

No âmbito dos direitos do aprendiz: é garantido o salário/hora. Uma pesquisa realizada no ano de 2020, constatou média salarial dos aprendizes. Sendo essas: valores pagos para o cargo de jovem aprendiz no ano de 2020, sendo excluídos casos de negociação. O salário é em média $\mathrm{R} \$ 711,55$ por 24 horas semanais trabalhadas. Sendo tabelado: salário/hora R\$ 4,26; 20 horas semanais - $\mathrm{R} \$ 440,19$; 40 horas semanais $\mathrm{R} \$$ 880,38; jovem aprendiz bancário 20 horas semanais $\mathrm{R} \$ 537,90$; e 30 horas semanais $\mathrm{R} \$ 806,85$. (Redação, 2020)

Ainda sobre os direitos do jovem aprendiz: a esse contrato são aplicadas as disposições da lei 8.036/90, garantindo a contribuição para o fundo de garantia e o seguro-desemprego, terá direito a férias e a vale-transporte.

De acordo com a legislação, a empresa que contrata jovens aprendizes recebe benefício fiscal de pagar apenas $2 \%$ de FGTS, estar dispensada de aviso prévio remunerado e a não obrigatoriedade de pagar multa rescisória nesse caso. De forma geral, existem outras vantagens como ter um diferencial no mercado pois a empresa passa a receber um novo olhar por parte dos clientes como uma marca que visa o futuro e está aberta a inovações; desenvolver o perfil de profissionais que são da necessidade da empresa pois ao contratar um jovem, esse não carrega consigo vícios de outros empregos o que facilita o desenvolvimento dentro do perfil da empresa; trabalhar a responsabilidade social pois colaboram na diminuição do trabalho infantil, influenciam no processo educativo dos jovens, etc.; e torna-se mais criativa e inovada a medida que os jovens têm grandes perspectivas de futuro e criatividade, criando um ambiente de trabalho renovado até para os colaboradores que estão há mais tempo na empresa.

Nesse sentido, observa-se muitos programas de aprendizagens, dentre eles destaca-se o Programa Jovem Aprendiz do CIEE (Centro de Integração Empresa Escola) que é uma associação civil de direito privado, sem fins lucrativos e de fins não econômicos, prestadora a assistência social, colaboradora na profissionalização e inserção de milhares de jovens no mercado de trabalho.

Pesquisas relatam que jovens que foram aprendizes no passado estão melhores no mercado que seus concorrentes e estudos demonstram que os profissionais que participaram do projeto quando jovens destacam-se dos demais em todos os aspectos, inclusive nas entrevistas e estão melhor adaptados no mercado de trabalho e que o programa influenciou muitos jovens nas escolhas de qual carreira seguirem, inclusive os aprendizes que atuaram no Ministério Público. (Braziliense, 2019)

Alguns relatos foram pontuados em pesquisas com esses profissionais e comentários positivos destacam-se como: "adquirir realização profissional”, "trabalho...nos dá dignidade”, "é onde vou começar uma aprendizagem”, “para adquirir experiência", "ter independência". "independência financeira". (Campos, 2009).

O jovem aprendiz no Ministério Público:

O Ministério Público, consoante o art. 127, caput, da Constituição Federal, é instituição permanente, essencial à função jurisdicional do Estado, incumbindo-lhe a defesa da ordem jurídica, do regime democrático e dos interesses sociais e individuais indisponíveis. (Janeiro, 2021) 
No Brasil é uma instituição autônoma e independente, que não está subordinada aos Poderes Executivo, Legislativo ou Judiciário e que fiscaliza o cumprimento da lei, sendo sua finalidade a defesa da democracia, da ordem jurídica, e dos interesses sociais e individuais indisponíveis.

O Ministério Público (MP) compreende jovens do programa Jovem Aprendiz. Esses são encaminhados ao órgão pelo CIEE, assim como toda empresa, os jovens possuem os mesmos direitos e deveres.

Destaca-se nesse contexto a familiaridade que o jovem adquire com a rotina da prática jurídica, o contato com os casos gerados no MP, com as pessoas necessitadas de auxílio jurídico, com definições do que é democracia, cidadania, direitos e deveres, as leis. Aspectos esses que fizeram com que muitos escolhessem a carreira jurídica.

\section{Considerações Finais}

Após a revisão literária, cabe ressaltar a pertinência em países em desenvolvimento, como o Brasil, de incentivos por parte do Estado no que diz respeito a qualificação profissional e conseguinte imersão no mercado de trabalho de adolescentes e jovens.

Evidencia-se que a educação no Brasil precisa de maiores incentivos, reformas e melhorias, e que projetos como o Jovem Aprendiz necessitam ser multiplicados e melhor compreendidos como um caminho eficiente de gerar uma renda extra para as famílias, sem prejuízo no processo educativo, e sim como incentivador.

Há muitas razões, mas é pertinente mencionar não somente a necessidade financeira das famílias contempladas pelo projeto, a inclusão social de jovens infratores, e o incentivo fiscal dado as empresas contratantes como também, e principalmente, para este estudo a experiência profissional que incide na vida do adolescente como incentivo ao estudo e à qualificação profissional, acrescentando a muitos um vislumbre de um futuro promissor e real. Validando tal afirmativa Fica evidente que jovens que foram aprendizes no passado, hoje estão melhores no mercado que seus concorrentes que não participaram do programa (segundo o Jornal Correio Brasiliense, 25/03/2019). O que torna ainda mais valiosa esta experiência, até mesmo pelo fato de que na hora de entrevistas de emprego os jovens que possuem algum tipo de contato com o trabalho podem levar algum tipo de vantagem sobre os outros (e essa tem sido uma tendência).

Nesse último faz-se menção a escolha da área de atuação. Os jovens que possuem essa experiência, têm menos dificuldades em escolher suas carreiras, como é o caso de alguns que ao trabalharem no Ministério Público, optaram por uma carreira.

O projeto Jovem Aprendiz evidencia por seus desdobramentos positivos em diversos níveis da economia, sociedade e educação que existem meios possíveis e reais de apoiar os jovens, orientando-os, estimulando-os e mostrando que cabe a eles a atitude de querer a mudança, e de se esforçarem para serem bem-sucedidos.

No âmbito individual, o Jovem Aprendiz agrega valor à vida de milhares de adolescentes, validando-os como seres humanos capazes de gerar renda, sem prejuízo próprio e de outrem, e que é possível ajudar a família de forma segura, articulada, com perspectivas de crescimento individual e profissional; e estimula aos demais a fazerem o mesmo.

\section{Referências}

Ávila, H., \& Sánchez, L. C. Teoría de los principios: Marcial Pons, 2011.

Barros, J. de. Qualificação Profissional. Brasil Escola

Barroso, L. R. O controle de constitucionalidade no direito brasileiro. (8a . ed.): Saraiva Educação SA, 2019.

Bello, E., Bercovici, G., \& Lima, M. Mont'A. B. O Fim das Ilusões Constitucionais de 1988? Revista Direito e Práxis. $10(3)$, $1769-1811$, jul/set. 2019. https://www.scielo.br/scielo.php?pid=S2179-89662019000301769\&script=sci_arttext

Brasil. Constituição (1988). Constituição da República Federativa do Brasil: Senado Federal: Centro Gráfico, 1988. 
Braziliense, Correio. $70 \%$ dos ex-jovens aprendiz estão trabalhando. $2019<$. /https://www.correiobraziliense.com.br/app/noticia/eu-estudante/trabalho-eformacao/2019/03/25/interna-trabalhoeformacao-2019,745024/pesquisa-mostra-que-70-dos-ex-jovens-aprendizes-estao-trabalhando.shtml>.

Camargo, M. F. C. de. A lei do menor aprendiz e suas consequências. 2016. < https://migalhas.uol.com.br/depeso/240678/a-lei-do-menor-aprendiz-e-suasconsequencias>. Campos, Franceline Souza. Projeto. Jovem Aprendiz

Ferreira, T. H. S., Farias, M. A., \& Silvares, E. F. de M. Adolescência através dos séculos. 2010 https://www.lume.ufrgs.br/bitstream/handle/10183/166760/Resumo_29706.pdf?

Gondim, S. M. G. Perfil do profissional e mercado de trabalho. Universidade Federal da Bahia

Idesproenor: percepção do adolescente sobre sua inserção no mundo do trabalho. 2009. https://1library.org/document/yee87m7y-projeto-jovem-aprendizidespromenor-percepcao-adolescente-insercao-trabalho.html.

Janeiro, Ministério Público do Estado do. 2021. O que é o Ministério Público? <http://www.mprj.mp.br/conheca-o-mprj/sobre-a-instituicao>.

Jovens, Em encontro de juventude do Mercosul, empresas se comprometem a criar 45 mil oportunidades profissionais. Ministério da mulher, da família e dos Direitos Humanos.. < https:/www.gov.br/mdh/pt-br/assuntos/noticias/2019/outubro/compromisso-com-a-juventude-e-reafirmado-em-encontro-de-jovens-domercosul>.

Junior, P. G. A quarta Revolução Industrial em pleno século XXI. Espaço Democrático. < https://espacodemocratico.org.br/artigos/a-quarta-revolucaoindustrial-em-pleno-seculo-xxi/.

Mandelli, M. T. Correndo atrás de seu projeto de vida: um estudo com participantes do Programa Jovem Aprendiz. 2011. <.https://repositorio.ufsc.br/handle/123456789/95446>.

Martins, T. A importância de cargos e salários. RH Portal Cargos e salários

Mercosul, $1^{o}$ encontro de jovens do MERCOSUL. < https://www.mercosur.int/pt-br/1o-encontro-de-jovens-do-mercosul/>.

Mercosul, Observatório de mercado de trabalho. Informe sobre o emprego juvenil no http://www.observatorio.net/Contenido/Informe\%20MERCOSUR\%20_OMTM_PORT\%20DOC.pdf>

Redação. Cargos e Salários Jovem Aprendiz 2021 - Tabela Salarial do Menor Aprendiz. 2020. < https://www.salario.com.br/tabela-salarial/aprendiz>.

Rosado, E. G. Contrato de aprendizagem: características e pontos controvertidos. 2016. https://migalhas.uol.com.br/depeso/248242/contrato-deaprendizagem--caracteristicas-e-pontos-controvertidos.

Silva, S. Inserção do jovem no mercado de trabalho. Brasil Escola 